\title{
Altered acrylic acid concentrations in hard and soft corals exposed to deteriorating water conditions
}

\author{
Lori S.H. Westmoreland ${ }^{\mathrm{a} \star}$, Jennifer N. Niemuth ${ }^{\mathrm{a}}$, Hanna S. Gracz ${ }^{\mathrm{ab}}$, and Michael K. Stoskopf ${ }^{\mathrm{a}}$ \\ a Environmental Medicine Consortium, College of Veterinary Medicine, North Carolina State University, \\ Raleigh, NC 27607, USA; ${ }^{\mathrm{b}}$ Department of Molecular and Structural Biochemistry, North Carolina State \\ University, Raleigh, NC 27607, USA \\ *1swestmo@ncsu.edu
}

\begin{abstract}
A reliable marker of early coral response to environmental stressors can help guide decision-making to mitigate global coral reef decline by detecting problems before the development of clinically observable disease. We document the accumulation of acrylic acid in two divergent coral taxa, stony small polyp coral (Acropora sp.) and soft coral (Lobophytum sp.), in response to deteriorating water quality characterized by moderately increased ammonia $(0.25 \mathrm{ppm})$ and phosphate $(0.15 \mathrm{ppm})$ concentrations and decreased calcium (360 ppm) concentration, using nuclear magnetic resonance spectroscopy (NMR)based metabolomic techniques. Changes in acrylic acid concentration in polyp tissues free of zooxanthellae suggest that acrylic acid could be a product of animal metabolism and not exclusively a metabolic by-product of the osmolyte dimethylsulfoniopropionate (DMSP) in marine algae or bacteria. Our findings build on previously documented depletions of acrylic acid in wild coral potentially correlated to temperature stress and provide additional insight into approaches to further characterize the nature of the metabolic accumulation of acrylic acid under controlled experimental conditions.
\end{abstract}

Key words: water quality deterioration, hard and soft coral metabolomics, Acropora sp., Lobophytum sp., nuclear magnetic resonance spectroscopy, acrylic acid concentration

Citation: Westmoreland LSH, Niemuth JN, acrylic acid concentrations in hard and soft corals exposed to deteriorating water conditions. FACETS 2: 531-544. doi: I 0. I | 39/facets-20 I 6-0064

Editor: Robie W. Macdonald

Received: November 9, 2016

Accepted: May 5, 2017

Published: June 27, 2017

Copyright: (c) 2017 Westmoreland et al. This work is licensed under a Creative Commons Attribution 4.0 International License (CC BY 4.0), which permits unrestricted use, distribution, and reproduction in any medium, provided the original author(s) and source are credited.

Published by: Canadian Science Publishing

\section{Introduction}

Traditional health evaluation methods (e.g., culture, cytology, and histopathology) are increasingly employed to evaluate coral health (Stoskopf 2011). However, key early markers of coral health decline are needed for effective early preventative health management decisions to protect coral communities. The use of advanced metabolomic techniques to determine baseline physiologic function in corals and study of their responses to disease and environmental stressors can help identify early diagnostic markers of coral health status (Viant et al. 2002, 2003; Viant 2007; Tjeerdema 2008). Use of emerging NMR-based metabolomic techniques in soft corals from different geographic locations has provided early evidence of the broad usefulness of these methods (He et al. 2014).

The purpose of the work we report here was to investigate changes in the metabolite profiles of two taxonomically widely separated corals, a stony small polyp coral (Acropora sp.) and a soft coral (Lobophytum sp.), during their responses to an unplanned water quality deterioration in the system housing them. This opportunity arose during an untargeted study of coral baseline metabolomes where we were evaluating metabolomics methods for sample collection, storage, and extraction 
protocols for coral samples, and performing metabolic fingerprinting using ${ }^{1} \mathrm{H}-\mathrm{NMR}$ spectroscopy on colonies maintained under good water quality conditions that had supported vigorous coral growth.

\section{Materials and methods}

\section{Animal management, water quality monitoring, and biopsy sampling}

The corals examined in this study were housed in a long established ( $>10$ year) 180 gallon glass aquarium equipped with $14000 \mathrm{k}$ metal halide (Plusrite, Ontario, California, USA) and VHO actinic (UV Lighting Company International, Brook Park, Ohio, USA) lights, protein skimmer, and ReeFlo Dart pump (ReeFlo Pumps, Colorado Springs, Colorado, USA). The aquarium community comprised various species of hard corals (Acropora sp., Caulastrea sp., Euphyllia sp., Galaxea sp., Hydnophora sp., Montipora sp., Seriatopora sp.), soft corals (Cladiella sp., Discosoma sp., Lobophytum sp., Plexaurella sp., Protopalythoa sp., Ricordea sp., Sarcophyton sp., Sinularia sp., Zoanthus sp.), and fishes (Zebrasoma velifer, Zebrasoma flavescens, Centropyge loriculus, Amphiprion frenatus, Chromis viridis). Fishes and corals were fed a mixed diet of green and red algae (Ocean Nutrition, Newark, California, USA) and commercial frozen fish/coral food (San Francisco Bay Brand, Inc., Newark, California, USA). Water quality parameters such as temperature, salinity by specific gravity, $\mathrm{pH}$, ammonia (salicylate test), nitrite, nitrate, calcium (precipitation/titration test), phosphate (orthophosphate test), and alkalinity were routinely monitored on a weekly basis, as well as at the times of sample collection for metabolomic assessment using commercial colorimetric test kits commonly used in the management of artificial sea water systems (API, Chalfont, Pennsylvania, USA). Sudden changes in three water quality parameters taken in aggregate characterized a decline in water quality that was recognized as needing immediate remediation to minimize impending impacts on coral health (Delbeek and Sprung 1994; Borneman 2001). The accuracy of colorimetric rapid test kits relative to standard validated bench chemistry methods varies substantially by test, but they generally provide sufficient precision to support water management decisions in aquaculture, and their use is a common practice in small- to medium-sized systems to support water quality management decisions made by biologists and farmers (Naigaga et al. 2016). To optimize accuracy and precision, it is important to use kits that are in date and properly stored, and to follow the directions carefully (Naigaga et al. 2016), as was done for the system in this study. Quality control of API commercial test kits to assure agreement with laboratory prepared standards is conducted by lot prior to distribution to consumers by the manufacturer, Mars Fishcare (GJ. Jones, personal communication, 2017). A limited number of individuals conducted the routine water testing of the aquarium system we examined, using in-date kits properly stored away from light and heat. Unexpected changes in test results were repeated with a fresh kit by multiple aquarists. The sudden simultaneous aggregate change in readings of three separate water quality parameters based on different underlying chemical reactions further strengthened our confidence that a change in water quality had occurred. The limits of detection for the three water parameter test kits that showed changes due to water quality decline are $0 \mathrm{mg} / \mathrm{L}$ for ammonia, $20 \mathrm{mg} / \mathrm{L}$ for calcium, and $0 \mathrm{mg} / \mathrm{L}$ for phosphate. After the collection of coral samples used in this study to represent corals in declining water quality, subsequent monitoring of the system water and coral health confirmed our interpretation. The three water quality parameters continued to worsen, as did other parameters, reaching conditions where frank coral loss occurred before the extensive mitigation efforts of water changes and system reconstruction returned the system to stability. Ammonia in a healthy reef system is rapidly removed through bacterial reduction to nitrite, and concentrations detectable with colorimetric tests provide warning of an inability of biofilter organisms to sufficiently reduce bio-wastes. Detectable inorganic phosphate concentrations can indicate an unexpected phosphate source or be an indication of protein skimmer inefficiency or loss of phosphate fixing organisms in biofilters. Elevated phosphates can support excessive algal growth and the depletion of water calcium concentrations necessary for coral skeletal growth. Water calcium concentrations are monitored 
Table 1. Routine water quality test results for the five months prior to the sampling of corals under good water quality conditions for ${ }^{1} \mathrm{H}-\mathrm{NMR}$ analysis.

\begin{tabular}{lcccc} 
Water quality parameter & Mean & Range & Mode & \% of total readings \\
\hline Temperature $\left({ }^{\circ} \mathrm{C}\right)$ & 25 & $24-27$ & 24 & 50 \\
Specific gravity & 1.024 & $1.023-1.025$ & 1.024 & 50 \\
$\mathrm{pH}$ & 8.2 & $8.1-8.4$ & 8.2 & 67 \\
Ammonia $(\mathrm{mg} / \mathrm{L})$ & 0 & $0-0$ & 0 & 100 \\
\hline Nitrite $(\mathrm{mg} / \mathrm{L})$ & 0 & $0-0$ & 0 & 100 \\
Nitrate $(\mathrm{mg} / \mathrm{L})$ & 0 & $0-0$ & 0 & 100 \\
\hline Calcium $(\mathrm{mg} / \mathrm{L})$ & 430 & $400-500$ & 400 & 50 \\
\hline Phosphate $(\mathrm{mg} / \mathrm{L})$ & 0 & $0-0$ & 0 & 100 \\
\hline
\end{tabular}

Note: All water quality test kits used were in date and stored properly. Water quality testing was routinely completed by a small number of individuals.

for depletions of the mineral critical for coral skeleton growth. Parameters considered optimal for this aquarium were $0 \mathrm{ppm}$ ammonia, $0 \mathrm{ppm}$ phosphate, and $\geq 420 \mathrm{ppm}$ calcium. A summary of water quality testing over the period of the metabolomics investigations is provided in Table 1 , showing the stability of the system prior to the sudden water quality deterioration event due to unknown cause(s).

Coral samples were collected at two time points. Multiple small samples (ranging from 219.8 to $453.7 \mathrm{mg}$ ) were collected from the distal tips of a colony of stony small polyp coral (Acropora sp.) and soft coral (Lobophytum sp.) maintained under water quality conditions that had supported vigorous coral growth. One sample was processed for metabolomics analysis as described below, and the rest were stored at $-80{ }^{\circ} \mathrm{C}$ for future work.

The same coral colonies were sampled for the second time $445 \mathrm{~d}$ later in a similar manner, $11 \mathrm{~d}$ after an unplanned acute aquarium water quality decline characterized by moderately increased ammonia $(0.25 \mathrm{ppm})$ and phosphate $(0.15 \mathrm{ppm})$ and moderately decreased calcium (360 ppm). At this time, the sampled corals showed clinical signs of distress with bleaching and algal growth where corals had previously exhibited active growth. Coral samples obtained from each collection were immediately frozen at $-79^{\circ} \mathrm{C}$ to quench enzymatic activity and minimize the oxidative destruction of susceptible metabolites. This was done by placing tissue samples directly in $\sim 1 \mathrm{~cm}$ diameter $\times \sim 2.5 \mathrm{~cm}$ deep wells drilled into a dry ice block. Snap frozen coral samples were transferred to individual cryogenic tubes and then to a $-80{ }^{\circ} \mathrm{C}$ freezer for storage prior to extraction with coral from deteriorated water quality conditions. Flash-frozen deteriorated water quality coral samples were processed without storage within $30 \mathrm{~min}$ of collection. Individual, similarly sized coral samples were selected from each deep frozen cohort for each type of NMR experiment and for the zooxanthellae-dissociated polyp experiments.

\section{Sample processing and NMR data acquisition}

All samples were kept on wet ice throughout processing. Each sample was weighed, then 2:1 $(v / w)$ of amphibian Ringer's (Thermo Fisher Scientific Inc., Waltham, Massachusetts, USA) was added. A $1.4 \mathrm{~mm}$ stainless steel bead blend (Next Advance, Inc., Averill Park, New York, USA) was added at a ratio of 1:1 $(v / v)$, and the samples were placed in a Bullet Blender (Next Advance, Inc., Averill Park, New York, USA) on speed 8 for $3 \mathrm{~min}$. The homogenized samples were centrifuged at 
$13000 \mathrm{~g}$ for $25 \mathrm{~min}$. The supernatants of all samples were collected and re-frozen at $-80{ }^{\circ} \mathrm{C}$ and stored for $17 \mathrm{~d}$ prior to NMR analysis.

Extracts were thawed on wet ice and pipetted into a 96-well MultiScreen filter plate with Ultracel-10 membrane (Millipore Ltd., Carrigtwohill, Ireland) that had previously been prepared by soaking and multiple washes with ultrapure water. The plate was centrifuged at $3000 \mathrm{~g}$ for $60 \mathrm{~min}$ at $21^{\circ} \mathrm{C}$, then $100 \mu \mathrm{L}$ of Milli-Q water (Merck KGaA, Darmstadt, Germany) was added to each well, and centrifugation was repeated. The resulting filtrates were lyophilized (Savant ISS110 SpeedVac Concentrator, Thermo Fisher Scientific Inc., Waltham, Massachusetts, USA), resuspended in $50 \mu \mathrm{L}$ $100 \%$ deuterium oxide with $20 \mathrm{mmol} / \mathrm{L}$ phosphate buffer, $0.1 \mathrm{mmol} / \mathrm{L}$ TSP, and $1 \mathrm{mmol} / \mathrm{L}$ formate (Sigma-Aldrich, St. Louis, Missouri, USA), and placed in $5 \mathrm{~mm}$ NMR tubes (Wilmad-LabGlass, Vineland, New Jersey, USA). ${ }^{1} \mathrm{H}$ spectra were acquired on a $14.1 \mathrm{~T}$ Varian INOVA $600 \mathrm{MHz}$ spectrometer at $25^{\circ} \mathrm{C}$. A one-pulse sequence with pre-saturation of the water resonance using a $90^{\circ}$ flip angle and a total repetition time of $12.65 \mathrm{~s}$ was used to obtain the ${ }^{1} \mathrm{H}$ spectra.

A combination of homonuclear ${ }^{1} \mathrm{H}$, heteronuclear ${ }^{1} \mathrm{H}$, and ${ }^{13} \mathrm{C}$ correlated NMR methods were applied to confirm the structure and identity of acrylic acid. These $1 \mathrm{D}$ and 2D pulsed field NMR experiments were performed on a Bruker AVANCE $700 \mathrm{MHz}$ spectrometer with cryoprobe $\mathrm{CP} 10 \mathrm{~K}$ at ${ }^{1} \mathrm{H}$ frequency $700.17 \mathrm{MHz}$ and ${ }^{13} \mathrm{C}$ frequency $176.05 \mathrm{MHz}$ at $25^{\circ} \mathrm{C}$ using Bruker Topspin 3.1 software (Bruker, Karlsruhe, Germany).

\section{Data processing}

Data were processed with ACD Labs 12.0 1D NMR Processor (Advanced Chemistry Development, Toronto, Ontario, Canada). Data processing included zero filling to 16000 points, Fourier transformation, phase correction, baseline correction, and alignment of the reference TSP signal. For quantitative metabolite analysis, regions containing residual water and those upfield of TSP or downfield of $9.0 \mathrm{ppm}$ were excluded. Intelligent bucket integration was used with a bin width of $0.04 \mathrm{ppm}$. The common integrals were normalized by dividing each bin by the sum of all the integrals per sample. To refine quantitative comparison of spectra across water conditions, for each compound of interest, the metabolite concentrations (the area under the curve of the summation of major peaks uncomplicated by peak overlap) were adjusted by dividing by the gross weight of the original coral sample. Chenomx NMR Suite 7.63 (Chenomx, Edmonton, Alberta, Canada), the Human Metabolome Database (Wishart et al. 2013), the Yeast Metabolome Database (Jewison et al. 2012), and the Spectral Database for Organic Compounds (National Institute of Advanced Industrial Science and Technology 2016) were used for peak identification.

\section{Studies of coral tissue dissociated from zooxanthellae}

The identification of acrylic acid as a key potential marker of coral response to water quality deterioration raised the question of whether this was a coral response or a response of the symbiotic zooxanthellae. To assess this, we isolated coral polyp tissues from zooxanthellae using methods modified from Banaszak (2007). Frozen samples of Acropora sp. and Lobophytum sp. were weighed (Acropora sp. $791.3 \mathrm{mg}$ and Lobophytum sp. $207.8 \mathrm{mg}$ ). Coral tissue was scraped off the underlying structure with a sterile scalpel blade and placed in an Eppendorf tube with $1 \mathrm{~mL}$ amphibian Ringer's solution. Tissue was homogenized at $20000 \mathrm{rpm}$ for $20 \mathrm{~s}$ with an Omni Prep Multi-Sample Homogenizer (OMNI International: The Homogenizer Company, Kennesaw, Georgia, USA). Coral tissue homogenates were centrifuged at $16000 \mathrm{~g}$ for $10 \mathrm{~min}$; the coral supernatant was saved, and the zooxanthellae pellet was discarded. The supernatant was centrifuged twice more at $16000 \mathrm{~g}$ for 10 min, discarding the zooxanthellae pellet each time. Ten microliters of the final isolated coral animal tissue supernatant was placed in a Neubauer improved hemocytometer 
(INCYTO, Chungnam-do, Korea) to count zooxanthellae cells and assess for contamination. Zooxanthellae contamination of coral animal tissue isolates was further tested with evaluation for chlorophyll a absorbance spectrophotometrically (wavelengths 430 and $662 \mathrm{~nm}$ ) (Nanodrop 1000, Thermo Fisher Scientific, Inc., Waltham, Massachusetts, USA). Coral tissue isolate samples were frozen at $-80{ }^{\circ} \mathrm{C}$, lyophilized at $-85^{\circ} \mathrm{C}$ (FreeZone Plus 2.5, Labconco, Kansas City, Missouri, USA), and rehydrated with $400 \mu \mathrm{L} 10 \%$ deuterium oxide containing $0.1 \mathrm{mmol} / \mathrm{L}$ TSP. ${ }^{1} \mathrm{H}$ spectra were acquired on a Bruker AVANCE $500 \mathrm{MHz}$ spectrometer with Oxford Narrow Bore Magnet, HP XW 4200 Host Workstation, using Topspin 3.1 software version (Bruker, Karlsruhe, Germany) to test for the presence of acrylic acid in coral tissue isolates.

\section{Results}

The quality of the ${ }^{1} \mathrm{H}$-NMR spectra obtained supported metabolomic analysis. Minimal line broadening, between 1.09 and $2.85 \mathrm{~Hz}$, indicated minimal interaction between the reference compound TSP and protein components of coral extracts, supporting its use in lieu of formate as an internal reference standard (Kriat et al. 1992). Metabolites identified in Acropora sp. and Lobophytum sp. are provided in Table 2. Spectra from Acropora sp. in good water quality and deteriorating water conditions are provided in Fig. 1. Similar data for Lobophytum sp. are provided in Fig. 2.

Table 2. List of metabolites identified in the ${ }^{1} \mathrm{H}$-NMR spectra of both coral species (Acropora sp. and Lobophytum sp.) from good and deteriorated water quality conditions.

\begin{tabular}{|ll|}
$\begin{array}{l}\text { Metabolites } \\
\text { Alcohols }\end{array}$ & $\begin{array}{c}\text { Reference chemical shift (ppm) and } \\
\text { peak shape (br s, d, dd, ddd, dq, m, q, or s) }\end{array}$ \\
\hline Methanol & $3.34(\mathrm{~s})$ \\
\hline Alkaloids & \\
\hline Trigonelline & $4.428(\mathrm{~s}), 8.072(\mathrm{~m}), 8.826(\mathrm{~m}), 9.114(\mathrm{~s})$ \\
\hline Amino acids & \\
\hline Alanine & $1.47(\mathrm{~d}), 3.76(\mathrm{q})$ \\
\hline Betaine & $3.25(\mathrm{~s}), 3.89(\mathrm{~s})$ \\
\hline Carnitine & $2.43(\mathrm{dd}), 3.21(\mathrm{~s}), 3.42(\mathrm{~m}), 4.56(\mathrm{br})$ \\
\hline Glycine & $3.54(\mathrm{~s})$ \\
\hline Valine & $0.976(\mathrm{~d}), 1.029(\mathrm{~d}), 2.261(\mathrm{~m}), 3.601(\mathrm{~d})$ \\
\hline Amino acid derivatives & \\
\hline N,N-Dimethylglycine & $2.91(\mathrm{~s}), 3.71(\mathrm{~s})$ \\
\hline Alkylamines & \\
\hline Dimethylamine & $2.7(\mathrm{~s})$ \\
\hline Trimethylamine & $2.89(\mathrm{~s})$ \\
\hline Fatty acids & \\
\hline Acetate & $1.91(\mathrm{~s})$ \\
\hline Acrylic acid & \\
\hline & $5.89(\mathrm{dd}), 6.14(\mathrm{q}), 6.40(\mathrm{dd}), 12.08(\mathrm{~s})$ \\
\hline
\end{tabular}


Table 2. (concluded)

\begin{tabular}{|c|c|}
\hline Metabolites & $\begin{array}{l}\text { Reference chemical shift (ppm) and } \\
\text { peak shape (br } s, d, d d, d d d, d q, m, q, \text { or } s)\end{array}$ \\
\hline Isovalerate & $0.9(\mathrm{~d}), 1.94(\mathrm{dq}), 2.05(\mathrm{~d})$ \\
\hline \multicolumn{2}{|l|}{ Guanidines } \\
\hline Methylguanidine $^{b}$ & $2.833(\mathrm{~s}), 3.366(\mathrm{~s})$ \\
\hline \multicolumn{2}{|l|}{ Organic acids } \\
\hline Formate $^{c}$ & $8.44(\mathrm{~s})$ \\
\hline Lactate & $1.32(\mathrm{~d}), 4.1(\mathrm{q})$ \\
\hline Malonate & $3.11(\mathrm{~s})$ \\
\hline \multicolumn{2}{|l|}{ Purine bases } \\
\hline Adenine & $8.11(\mathrm{~s}), 8.12(\mathrm{~s})$ \\
\hline \multicolumn{2}{|l|}{ Pyrimidine bases } \\
\hline Thymine & $1.86(\mathrm{~s}), 7.37(\mathrm{~s})$ \\
\hline \multicolumn{2}{|c|}{ Quaternary ammonium } \\
\hline Choline & $3.189(\mathrm{~s}), 3.507(\mathrm{dd}), 4.056(\mathrm{ddd})$ \\
\hline \multicolumn{2}{|l|}{ Sulfonyls } \\
\hline Dimethyl sulfone $e^{b}$ & $3.138(\mathrm{~s})$ \\
\hline
\end{tabular}

Note: Metabolites were identified using Chenomx NMR Suite 7.63 (Chenomx, Edmonton, Alberta, Canada), the Human Metabolome Database (Wishart et al. 2013), the Yeast Metabolome Database (Jewison et al. 2012), the Spectral Database for Organic Compounds (National Institute of Advanced Industrial Science and Technology 2016), and reference chemical shifts predicted from ACD Labs 12.0 1D NMR Processor (Advanced Chemistry Development, Toronto, Ontario, Canada). br s, broad singlet; d, doublet; dd, doublet of doublets; ddd, doublet of doublet of doublets; dq, doublet of quartets; m, multiplet; q, quartet; s, singlet.

${ }^{a}$ Actual chemical shifts identified on coral sample spectra for acrylic acid were $5.66 \mathrm{ppm}(\mathrm{dd})$, $6.02 \mathrm{ppm}(\mathrm{dd})$, and $6.13 \mathrm{ppm}(\mathrm{q})$.

${ }^{b}$ Only found in Lobophytum sp.

${ }^{c}$ Formate was added as a secondary reference standard, but was present in the pilot and feasibility study samples (which did not have exogenous formate).

The majority of identified metabolites in the polar metabolomes of the two species were parallel and included amino acids such as alanine, glycine betaine, glycine, and valine, organic acids such as formate (also added as a second internal standard), lactate, and malonate, as well as metabolites from fatty acid metabolism such as choline and acetate. Alkylamines, including dimethylamine and trimethylamine, and the pyrimidine base thymine, were also identified in both coral species. Other common metabolites of both coral species included trigonelline, methanol, and acrylic acid. Differences of note between the polar metabolomes of the two coral species were that methylguanidine and dimethyl sulfone were found in Lobophytum sp. but not Acropora sp. Spectra from Acropora sp. also contained more distinct peaks at chemical shifts consistent with carnitine and isovalerate.

When corals were exposed to deteriorating water quality, the most dramatic changes in abundant metabolite concentrations observed were the nearly twofold increases in acrylic acid and acetate 

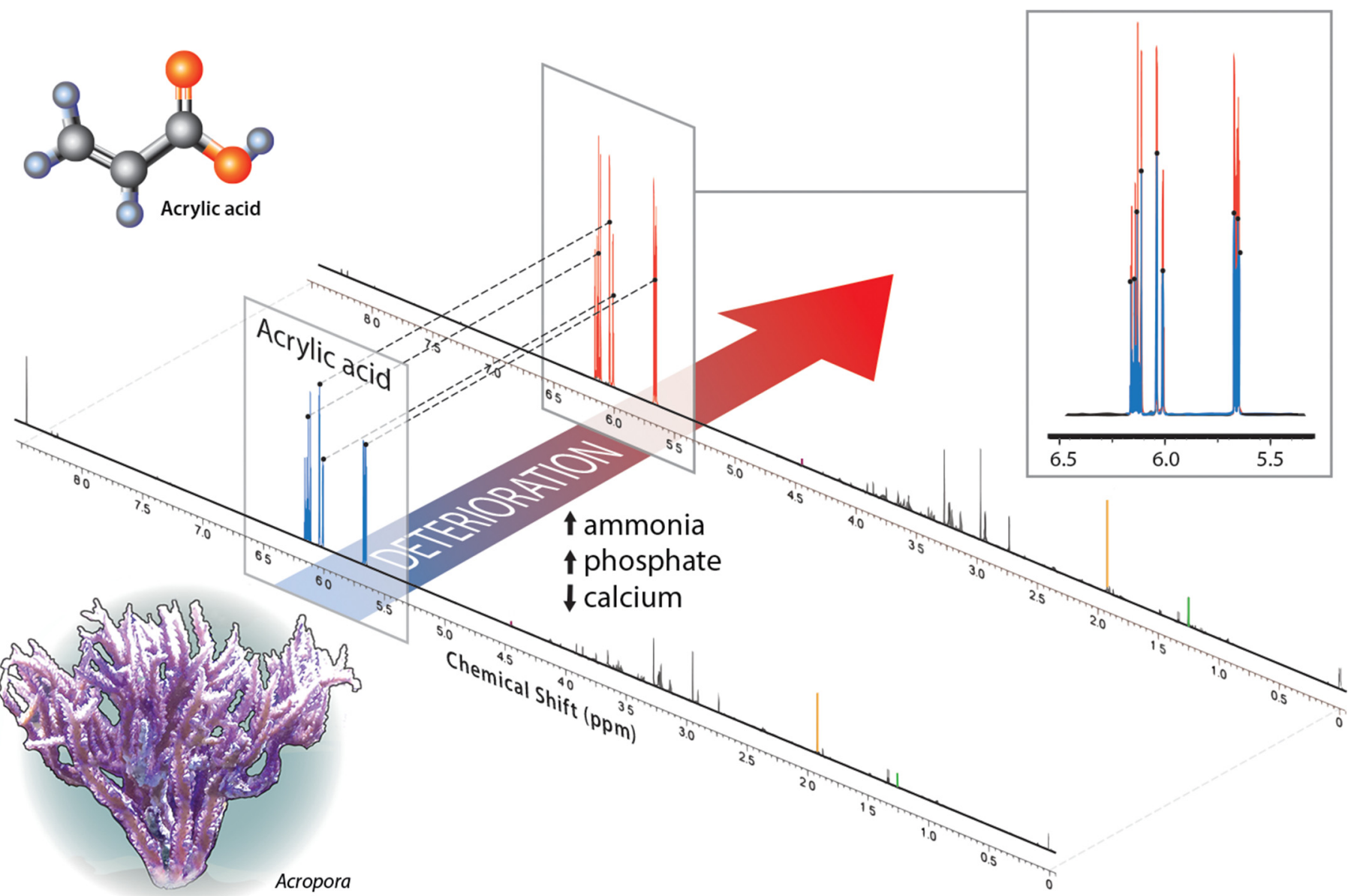

Fig. 1. A representative comparison of ${ }^{1} \mathrm{H}-\mathrm{NMR}$ spectra of Acropora sp. living in good water conditions and later exposed to an unplanned deterioration of water conditions suggests that increased concentrations of acrylic acid may be a useful marker of coral distress because of reduced availability of environmental calcium and increased ammonia and phosphate. Acrylic acid (5.66 ppm (dd), $6.02 \mathrm{ppm}(\mathrm{dd})$, and $6.13 \mathrm{ppm}(\mathrm{q}))$ concentrations in deteriorated water (red) are 1.8 times those found in corals living in good water (blue). Other metabolites with altered concentrations (acetate (orange) $1.91 \mathrm{ppm}(\mathrm{s})$; lactate (green) $1.32 \mathrm{ppm}$ (d) and $4.1 \mathrm{ppm}(\mathrm{q})$; trigonelline (purple) $4.4 \mathrm{ppm}(\mathrm{s}), 9.1 \mathrm{ppm}(\mathrm{s}), 8.07 \mathrm{ppm}(\mathrm{m})$, and $8.8 \mathrm{ppm}(\mathrm{m})$; thymine (too small to indicate in the figure) $1.86 \mathrm{ppm}(\mathrm{s})$ and $7.37 \mathrm{ppm}(\mathrm{s})$ ) were of much lower concentrations, making their quantitation less reliable. There is no $y$-axis in the figure because peak heights are schematic. d, doublet; dd, doublet of doublets; m, multiplet; q, quartet; s, singlet.

concentrations in both Acropora sp. and Lobophytum sp. Of particular note, acrylic acid was confirmed in isolated zooxanthellae-free polyp tissues from both coral species, suggesting animal tissue metabolic origin. The much lower concentrations of trigonelline also increased in both coral species exposed to deteriorated water, whereas tissue concentrations of lactate and thymine decreased. Metabolite concentration percent changes adjusted for coral sample weight are listed in Table 3.

\section{Discussion}

Metabolic profiles based on polar metabolites were obtained from very small samples using a nontoxic, readily obtained extraction solvent, amphibian Ringer's solution (Hurley-Sanders et al. 2016) that produced repeatable results, and may have some advantages over the use of pure water (Gordon et al. 2013) and other extraction methods. Arabinose and glucose, common monosaccharide components of Acropora sp. mucus (Wild et al. 2005), were not identified in our spectra suggesting 


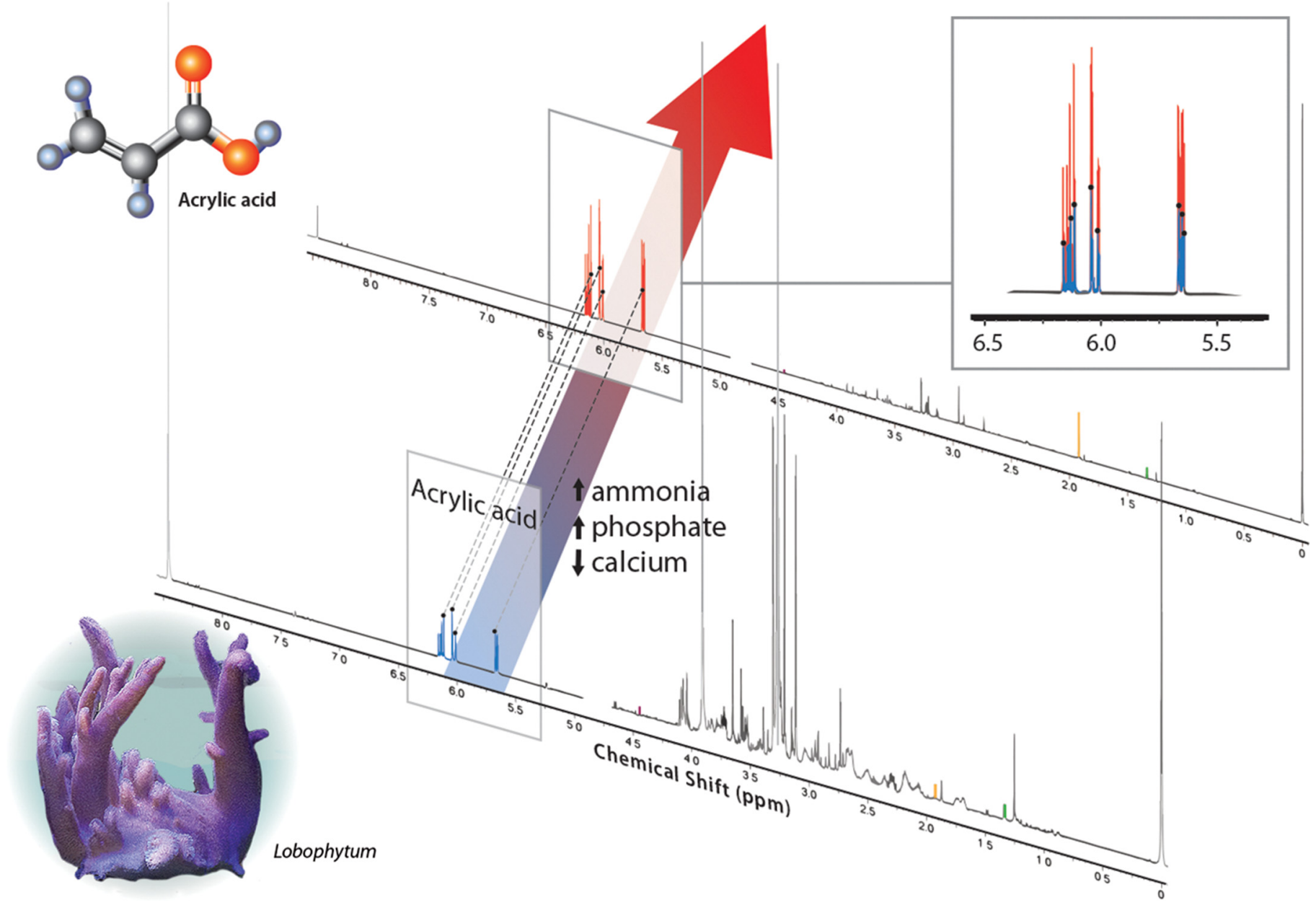

Fig. 2. A representative comparison of ${ }^{1} \mathrm{H}$-NMR spectra of Lobophytum sp. living in long-established good water conditions and of the same colony subjected to an unplanned deterioration of water conditions suggests that increased concentrations of acrylic acid may be a useful marker of coral stress because of reduced availability of environmental calcium and increased ammonia and phosphate. Acrylic acid (5.66 ppm (dd), $6.02 \mathrm{ppm}(\mathrm{dd})$, and 6.13 ppm (q)) concentrations in deteriorated water (red) are 1.9 times those found in corals living in good water (blue). Other metabolites with altered concentrations from exposure to deteriorated water conditions (acetate (orange) 1.91 (s) ppm; lactate (green) $1.32 \mathrm{ppm}$ (d) and $4.1 \mathrm{ppm}$ (q); trigonelline (purple) 4.4 ppm (s), 9.1 ppm (s), $8.07 \mathrm{ppm}$ (m), and $8.8 \mathrm{ppm}(\mathrm{m})$; thymine (too small to indicate in the figure) $1.86 \mathrm{ppm}(\mathrm{s})$ and $7.37 \mathrm{ppm}(\mathrm{s})$ ) had much lower concentrations in coral tissues making their quantitation more amenable to peak integration techniques. There is no $y$-axis in the figure because peak heights are schematic. d, doublet; dd, doublet of doublets; m, multiplet; q, quartet; s, singlet.

that mucus was a minimal component of our coral samples. The lack of DMSP and DMS in our spectra is of particular interest. Both compounds have received recent attention in coral metabolic studies, particularly in responses to thermal stress (Broadbent et al. 2002; Raina et al. 2013). Acrylic acid has been considered a breakdown product of DMSP, which is considered an osmolyte of algae and a major carbon source for marine bacteria (Reisch et al. 2013). It is possible that our extraction and homogenization method produced a sample that de-emphasizes metabolites of zooxanthellae. A focused effort to process coral tissues avoiding zooxanthellae rupture or inclusion yielded similar results to our standard protocol, supporting this conjecture.

The metabolomes of the two coral genera from different orders were very similar. Metabolites identified from both coral genera included amino acids, pyrimidines, alkylamines, organic acids, 
Table 3. Area under curve quantitation for key metabolites from Acropora sp. and Lobophytum sp. from good and deteriorated water quality conditions.

\begin{tabular}{|c|c|c|c|}
\hline & $\begin{array}{c}\text { Percent change } \\
\text { (deteriorated/good) }\end{array}$ & $\begin{array}{c}\text { Good water } \\
\text { (area under curve) }\end{array}$ & $\begin{array}{l}\text { Deteriorated water } \\
\text { (area under curve) }\end{array}$ \\
\hline \multicolumn{4}{|l|}{ Acropora sp. } \\
\hline Acrylic acid & 180 & 0.2133 & 0.3287 \\
\hline Acetate & 180 & 0.0108 & 0.0164 \\
\hline Lactate & 0 & 0.0042 & 0.0033 \\
\hline Thymine & -10 & 0.0008 & 0.0006 \\
\hline Trigonelline & 250 & 0.0004 & 0.0009 \\
\hline Sample weight (g) & - & 0.430 & 0.363 \\
\hline \multicolumn{4}{|l|}{ Lobophytum sp. } \\
\hline Acrylic acid & 190 & 0.0532 & 0.2134 \\
\hline Acetate & 180 & 0.0029 & 0.0108 \\
\hline Lactate & -70 & 0.0059 & 0.0042 \\
\hline Thymine & -90 & 0.0043 & 0.0008 \\
\hline Trigonelline & 0 & 0.0002 & 0.0004 \\
\hline Sample weight (g) & - & 0.220 & 0.454 \\
\hline
\end{tabular}

Note: The sum of areas under the curve for assigned ${ }^{1} \mathrm{H}-\mathrm{NMR}$ spectral peaks after normalization of the spectrum and adjustment based on the TSP internal standard for each compound of interest are presented. Percent changes are calculated for each compound for a given coral species by dividing the area under the curve for deteriorated water coral samples by the area under the curve for coral samples from good water and then multiplying by 100 times the ratio of the weights of the good over the deteriorated water coral samples originally processed for spectroscopy.

alcohols, and chemical species involved in fatty acid metabolism. Acropora sp. and Lobophytum sp. shared all but two of the identified metabolites. Samples from Lobophytum sp. contained methylguanidine and dimethyl sulfone, which were not found in Acropora sp. The overall similarity suggests the potential for the development of markers that are useful across broad coral taxonomic groups.

Metabolites did not appear de novo or disappear in either coral species in response to deteriorating water quality; however, concentrations of both acetate and acrylic acid increased. Acetate is important for the metabolism of fats, carbohydrates, and synthesis of acetyl-CoA, and is critical to TCA cycle production of energy through aerobic metabolism (Daintith 2008; Rosenthal and Glew 2009). Acetate may be formed from the hydrolysis of acetyl-CoA to facilitate the distribution of a carbon substrate in an organism experiencing anaerobic conditions (Knowles et al. 1974). Evidence also supports the metabolism and detoxification of acrylic acid to carbon dioxide and acetyl-CoA destined for the citric acid cycle via the pathway for the metabolism of propionate not dependent on vitamin B $_{12}$ (Finch and Frederick 1992). Therefore, an increase in acetate concentration in corals exposed to deteriorating water conditions may represent a shift to anaerobic metabolism and (or) an increase in catabolism of elevated concentrations of acrylic acid.

Acrylic acid concentrations rose dramatically in corals exposed to deteriorating water quality. Acrylic acid can be produced by multiple species of coral-associated bacteria, in addition to being present in 


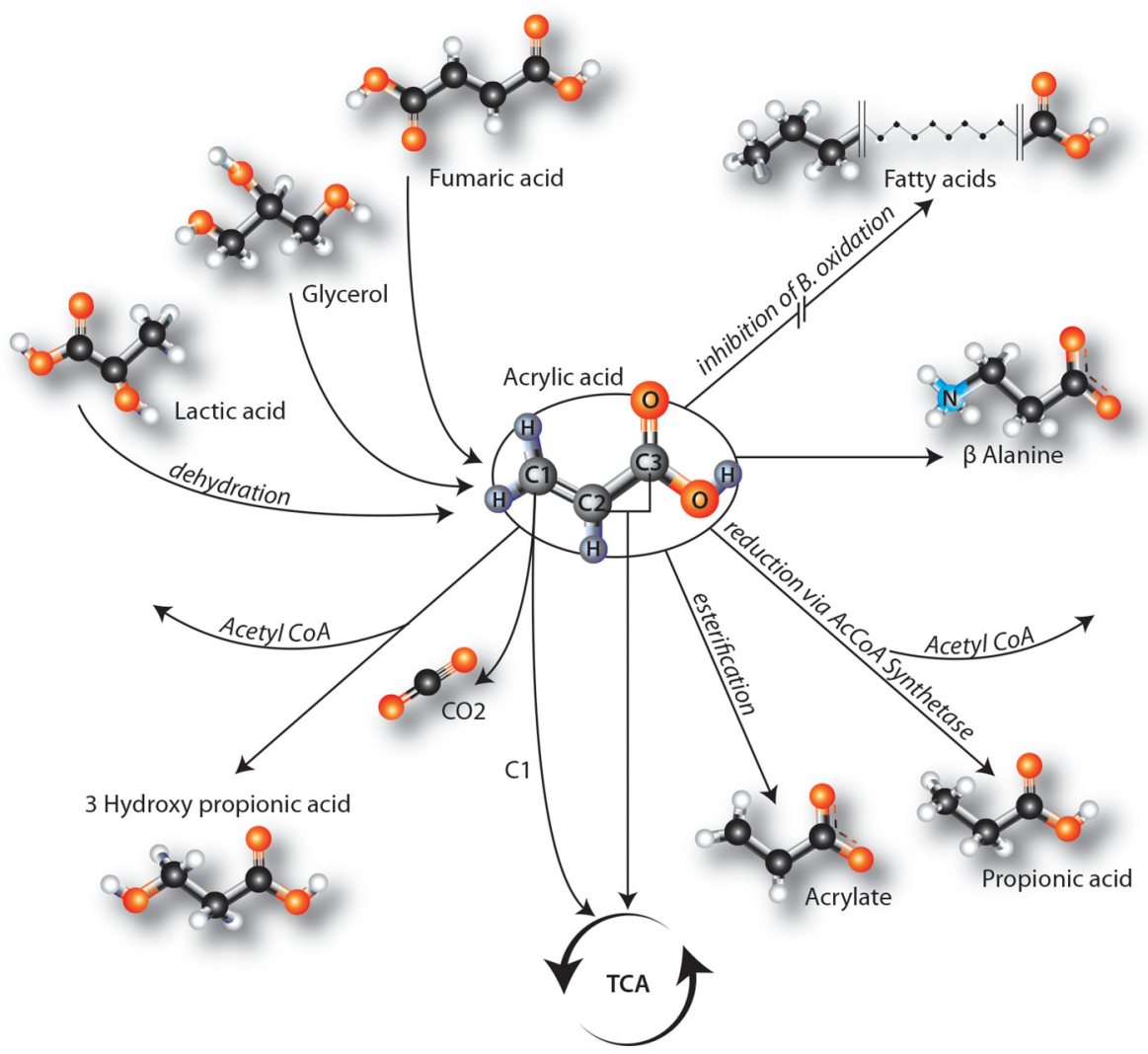

Fig. 3. Acrylic acid in coral tissues would be anticipated to have multiple metabolic interactions, as shown here. Acrylic acid would be expected to inhibit beta-oxidation of fatty acids and to drive the TCA acid cycle through two different pathways, with one generating carbon dioxide. In addition to serving as a precursor to acrylate through esterification, increasing acrylic acid concentrations would be expected to drive the formation of acetyl$\mathrm{CoA}$ in the production of 3-hydroxypropionic acid and propionic acid. Fumaric acid, glycerol, and lactic acid are among the potential precursors of coral-derived acrylic acid. TCA, tricarboxylic acid; acetyl-CoA, acetyl coenzyme-A.

coral tissue and coral mucus (Broadbent and Jones 2004; Raina et al. 2009). It has been implicated as both a bacteriostatic antibacterial agent and a carbon source for certain bacteria (Sieburth 1960; Slezak et al. 1994; Ansede et al. 2001; Raina et al. 2009). Quantitative bacterial assays were not part of our study design, but no evidence of dramatic shifts in bacterial loads of samples was observed. We cannot rule out the possibility that a bacterial metabolic response may contribute to increased acrylic acid concentrations observed in coral polyp tissues.

Acrylic acid has previously been identified in numerous species of hard coral, including Acropora sp. (Tapiolas et al. 2010, 2013), and reference has been made to a "carbon of methyl acrylate" from the soft coral Sinularia abrupta (Missakian et al. 1975, p. 2514). Our findings of increased acrylic acid concentrations contrast with reports of decreased acrylic acid content in wild corals exposed to thermal stress. Another study of marine algal cultures speculated that carbon dioxide or iron limitation, excess copper, and (or) hydrogen peroxide exposure might cause alterations in DMSP metabolism, and secondarily deplete acrylic acid pools (Sunda et al. 2002). Within the scope of our investigations, we can only speculate why we saw accumulation rather than depletion of acrylic acid in the corals we studied. It is reasonable to postulate that metabolic response to thermal stress could be distinct from 
responses to chemical stressors reported in our study. Thermal stress and potentially each of the individual chemical stressors are likely to have different effects on the anabolism and catabolism of both the coral animals themselves and their zooxanthellae, as well as the greater coral-associated biome of non-zooxanthellae algae, fungi, protozoa, and bacteria. The decrease in acrylic acid during thermal stress may represent an aggregate depletion of a key metabolite in a thermally stimulated growth phase of a coral or its associated biome, in the absence of other resource limitations, whereas the increase in acrylic acid we report may represent the accumulation of a metabolite that is either normally not as well used in either growth/reproductive inhibition or occurs in a shift to anaerobic metabolism.

We propose, however, that acrylic acid accumulation during exposure to deteriorated water quality could be a primary protective response to oxidative stress caused by excess ammonia rather than being related to the retardation of coral growth due to reduced calcification, and that this accumulation could occur through several metabolic pathways (Fig. 3) (Stoskopf 2011). Acrylic acid remains charged in aqueous environments at physiologic $\mathrm{pH}$ and has previously been proposed as a key component of the coral antioxidant system. It readily scavenges hydroxyl radicals and is more effective at scavenging reactive oxygen species than DMSP (Sunda et al. 2002). These properties would be particularly beneficial in coral tissues experiencing oxidative stress due to exposure to excess ammonia.

Our studies illustrate the usefulness of captive coral models as a research tool and ${ }^{1} \mathrm{H}-\mathrm{NMR}$ spectroscopy for the evaluation of the health and physiologic status of taxonomically divergent coral species. Conserved aspects of metabolomes, with specific metabolites serving as markers of stress, can inform better approaches to mitigation and preventative management of both captive and wild coral reefs.

\section{List of abbreviations}

$\begin{array}{ll}\text { NMR } & \text { nuclear magnetic resonance spectroscopy } \\ { }^{1} \text { H-NMR } & \text { proton nuclear magnetic resonance spectroscopy } \\ { }^{13} \text { C-NMR } & \text { carbon nuclear magnetic resonance spectroscopy } \\ \text { Acetyl-CoA } & \text { acetyl coenzyme-A } \\ \text { DMS } & \text { dimethylsulfide } \\ \text { DMSP } & \text { dimethylsulfoniopropionate } \\ \text { TCA } & \text { tricarboxylic acid } \\ \text { TSP } & \text { trimethylsilylpropanoic acid }\end{array}$

\section{Acknowledgements}

The authors thank the Macdonald Laboratory and UNC Metabolomics Facility at The Hamner Institutes for Health Sciences for their advice on NMR technique and Drs. Azcarate-Peril and Cadenas at the UNC Microbiome Core Facility for use of their spectrophotometer. This study was supported in part by funding from the Environmental Medicine Consortium and the North Carolina Aquariums.

\section{Author contributions}

Conceived and designed the study: LSHW, JNN, MKS. Performed the experiments/collected the data: LSHW, JNN, HSG. Analyzed and interpreted the data: LSHW, JNN, HSG, MKS. Drafted or revised the manuscript: LSHW, JNN, HSG, MKS. 


\section{Competing interests}

The authors have declared that no competing interests exist.

\section{Data accessibility statement}

All relevant data are within the paper and maintained by the authors in the data repository of the NCSU Center for Marine Sciences and Technology Marine Magnetic Resonance Facility (emc.ncsu. edu/research/facilities/marine-magnetic-resonance/mmrf-data-repository/).

\section{References}

Ansede JH, Friedman R, and Yoch DC. 2001. Phylogenetic analysis of culturable dimethyl sulfideproducing bacteria from a Spartina-dominated salt marsh and estuarine water. Applied Environmental Microbiology, 67(3): 1210-1217. PMID:11229912. doi:10.1128/AEM.67.3.1210-1217.2001.

Banaszak AT. 2007. Optimization of DNA extraction from a scleractinian coral for the detection of thymine dimers by immunoassay. Photochemistry and Photobiology, 83(4): 833-838. PMID:17645654. doi:10.1111/j.1751-1097.2007.00083.x.

Borneman EH. 2001. Aquarium corals: selection, husbandry, and natural history. TFH Publications, Neptune City, New Jersey. 464 p.

Broadbent AD, and Jones GB. 2004. DMS and DMSP in mucus ropes, coral mucus, surface films and sediment pore waters from coral reefs in the Great Barrier Reef. Marine and Freshwater Research, 55(8): 849-855. doi:10.1071/MF04114.

Broadbent AD, Jones GB, and Jones RJ. 2002. DMSP in corals and benthic algae from the Great Barrier Reef. Estuarine, Coastal and Shelf Science, 55(4): 547-555. doi:10.1006/ecss.2002.1021.

Daintith J. 2008. A dictionary of chemistry. 6th edition. Oxford University Press, New York, New York. 584 p.

Delbeek JC, and Sprung J. 1994. The reef aquarium: a comprehensive guide to the identification and care of tropical marine invertebrates (volume 1). Ricordea Publishing, Coconut Grove, Florida. 544 p.

Finch L, and Frederick CB. 1992. Rate and route of oxidation of acrylic acid to carbon dioxide in rat liver. Fundamental and Applied Toxicology, 19(4): 498-504. PMID:1426707. doi:10.1016/0272-0590 (92)90087-X.

Gordon BR, Leggat W, and Motti CA. 2013. Extraction protocol for nontargeted NMR and LC-MS metabolomics-based analysis of hard coral and their algal symbionts. In Metabolomics tools for natural product discovery: methods and protocols. Edited by U Roessner and DA Dias. Humana Press, New York, New York. pp. 129-147.

He Q, Sun R, Liu H, Geng Z, Chen D, Li Y, et al. 2014. NMR-based metabolomic analysis of spatial variation in soft corals. Marine Drugs, 12(4): 1876-1890. PMID:24686560. doi:10.3390/md12041876.

Hurley-Sanders J, Stoskopf MK, Nelson SAC, Showers W, Law JM, Gracz HS, et al. 2016. Tissue extraction methods for metabolic profiling of a freshwater bivalve, Elliptio complanata (Lightfoot, 1786). American Malacological Bulletin, 33(2): 185-194. doi:10.4003/006.033.0209. 
Jewison T, Knox C, Neveu V, Djoumbou Y, Guo AC, Lee J, et al. 2012. YMDB: the Yeast Metabolome Database. Nucleic Acids Research, 40(Database issue): D815-D820. PMID:22064855. doi:10.1093/ nar/gkr916.

Knowles SE, Jarrett IG, Filsell OH, and Ballard FJ. 1974. Production and utilization of acetate in mammals. Biochemical Journal, 142(2): 401-411. PMID:4441381. doi:10.1042/bj1420401.

Kriat M, Confort-Gouny S, Vion-Dury J, Sciaky M, Viout P, and Cozzone PJ. 1992. Quantitation of metabolites in human blood serum by proton magnetic resonance spectroscopy. A comparative study of the use of formate and TSP as concentration standards. NMR in Biomedicine, 5(4): 179-184. PMID:1449953. doi:10.1002/nbm.1940050404.

Missakian MG, Burreson BJ, and Scheuer PJ. 1975. Pukalide, a furanocembranolide from the soft coral Sinularia abrupta. Tetrahedron, 31(20): 2513-2515. doi:10.1016/0040-4020(75)80262-6.

Naigaga S, Boyd CE, Gaillard P, Abdelrahman HA, and Molnar JJ. 2016. Assessing the reliability of water-test kits for use in pond aquaculture. Journal of the World Aquaculture Society. doi:10.1111/ jwas.12377.

National Institute of Advanced Industrial Science and Technology. 2016. Spectral database for organic compounds [online]: Available from sdbs.db.aist.go.jp.

Raina J-B, Tapiolas DM, Willis BL, and Bourne DG. 2009. Coral-associated bacteria and their role in the biogeochemical cycling of sulfur. Applied and Environmental Microbiology, 75(11): 3492-3501. PMID:19346350. doi:10.1128/AEM.02567-08.

Raina J-B, Tapiolas DM, Forêt S, Lutz A, Abrego D, Ceh J, et al. 2013. DMSP biosynthesis by an animal and its role in coral thermal stress response. Nature, 502: 677-680. PMID:24153189. doi:10.1038/ nature12677.

Reisch CR, Crabb WM, Gifford SM, Teng Q, Stoudemayer MJ, Moran MA, et al. 2013. Metabolism of dimethylsulphoniopropionate by Ruegeria pomeroyi DSS-3. Molecular Microbiology, 89(4): 774-791. PMID:23815737. doi:10.1111/mmi.12314.

Rosenthal MD, and Glew RH. 2009. Medical biochemistry: human metabolism in health and disease. Wiley, Hoboken, New Jersey. 440 p.

Sieburth JM. 1960. Acrylic acid, an "antibiotic" principle in Phaeocystis blooms in Antarctic waters. Science, 132(3428): 676-677. PMID:14446452. doi:10.1126/science.132.3428.676.

Slezak DM, Puskaric S, and Herndl GJ. 1994. Potential role of acrylic acid in bacterioplankton communities in the sea. Marine Ecology Progress Series, 105(1-2): 191-197. doi:10.3354/meps105191.

Stoskopf MK. 2011. Coelenterates. In Invertebrate medicine. 2nd edition. Edited by GA Lewbart. Wiley, Ames, Iowa. pp. 21-56.

Sunda W, Kieber DJ, Kiene RP, and Huntsman S. 2002. An antioxidant function for DMSP and DMS in marine algae. Nature, 418: 317-320. PMID:12124622. doi:10.1038/nature00851.

Tapiolas DM, Motti CA, Holloway P, and Boyle SG. 2010. High levels of acrylate in the Great Barrier Reef coral Acropora millepora. Coral Reefs, 29(3): 621-625. doi:10.1007/s00338-010-0608-3. 
Tapiolas DM, Raina J-B, Lutz A, Willis BL, and Motti CA. 2013. Direct measurement of dimethylsulfoniopropionate (DMSP) in reef-building corals using quantitative nuclear magnetic resonance (qNMR) spectroscopy. Journal of Experimental Marine Biology and Ecology, 443: 85-89. doi:10.1016/j.jembe.2013.02.037.

Tjeerdema RS. 2008. Application of NMR-based techniques in aquatic toxicology: brief examples. Marine Pollution Bulletin, 57(6-12): 275-279. PMID:18282584. doi:10.1016/j.marpolbul.2008.01.002.

Viant MR. 2007. Metabolomics of aquatic organisms: the new 'omics' on the block. Marine Ecology Progress Series, 332: 301-306. doi:10.3354/meps332301.

Viant MR, Pincetich CA, Walton JH, Tjeerdema RS, and Hinton DE. 2002. Utilizing in vivo nuclear magnetic resonance spectroscopy to study sublethal stress in aquatic organisms. Marine Environmental Research, 54(3-5): 553-557. PMID:12408616. doi:10.1016/S0141-1136(02)00193-9.

Viant MR, Rosenblum ES, and Tjeerdema RS. 2003. NMR-based metabolomics: a powerful approach for characterizing the effects of environmental stressors on organism health. Environmental Science \& Technology, 37(21): 4982-4989. PMID:14620827. doi:10.1021/es034281x.

Wild C, Woyt H, and Huettel M. 2005. Influence of coral mucus on nutrient fluxes in carbonate sands. Marine Ecology Progress Series, 287: 87-98. doi:10.3354/meps287087.

Wishart DS, Jewison T, Guo AC, Wilson M, Knox C, Liu Y, et al. 2013. HMDB 3.0-the Human Metabolome Database in 2013. Nucleic Acids Research, 41(Database issue): D801-D807. PMID:23161693. doi:10.1093/nar/gks1065. 